\title{
CORRELAÇÃO ENTRE A NECROSE DE FRUTOS ASSOCIADA AO Colletotrichum SPP. COM AS CARACTERÍSTICAS FRUTOS POR NÓ E PRODUTIVIDADE ENTRE GENÓTIPOS DE CAFÉ ARÁBICA*
}

\author{
Correlation between fruit necrosis associated to Colletotrichum spp. with the fruits per \\ node and yield traits of arabic coffee
}

\author{
Gustavo Hiroshi Sera ${ }^{1}$, Tumoru Sera ${ }^{2}$, Dhalton Shiguer Ito ${ }^{1}$, José Alves de Azevedoº \\ Claudionor Ribeiro Filho ${ }^{3}$, Clayton Ribeiro Alegre ${ }^{3}$
}

\begin{abstract}
RESUMO
O fungo Colletotrichum spp. vem sendo associado à graves perdas para a cafeicultura brasileira. Objetivou-se neste trabalho verificar a existência de relação entre a variável necrose de frutos associada ao Colletotrichum spp. ("COL") com a quantidade média de frutos por nó produtivo ("FN") e com a produção ("PRD”) em genótipos de café arábica. O ensaio de campo foi realizado no IAPAR (Londrina, PR, Brasil) em dezembro de 2004 e em cafeeiros com três anos de idade. A variável "COL" foi avaliada atribuindose notas de 1 a 5 , onde 1 representam plantas com $0 \%$ a $5 \%$ de frutos necrosados. "FN" foi avaliada seguindo uma escala de notas de 1 a 5, onde 1 representa plantas com 0 a 3 frutos/ nó e nota 5 com mais do que 15 frutos/ nó. A avaliação visual subjetiva da produção foi estimada em litros de frutos em estádio cereja, por planta. A correlação de Pearson foi estimada para avaliar a existência de associações entre as variáveis. Foram observadas correlações positivas e significativas a $1 \%$ entre "COL" e "FN" e entre "COL" e "PRD". A necrose de frutos foi mais intensa em cafeeiros com mais produção e com mais frutos por nó produtivo. Sugere-se que a avaliação da resistência de campo à necrose dos frutos associada à presença de Colletotrichum spp. seja realizada em cafeeiros com alta produção e com alta quantidade de frutos por nó produtivo.
\end{abstract}

Termos para indexação: Antracnose, Coffea, Colletotrichum gloeosporioides, cultivares, melhoramento genético.

\section{ABSTRACT}

Different fungi species of genus Colletotrichum has been associated with losses to the Brazilian coffee crop. The aim of this research was to evaluate the association between the variable fruit necrosis associated to Colletotrichum spp. ("COL") with the fruits per productive node average ("FN") and between "COL" and the yield ("PRD") in Coffea arabica L. genotypes. The field assay was evaluated at IAPAR (Londrina, PR, Brazil), in December 2004 and on coffee trees with three years old. The "COL" variable was evaluated attributing scores from 1 to 5 , where score 1 represents plants with $0 \%$ to $5 \%$ of necrosed fruits. "FN" was evaluated following a score scale from 1 to 5 , where score 1 represents plants with 0 to 3 fruits/ node and score 5 with more than 15 fruits/ node. The yield per plant was estimated by visual evaluation in liters of cherry fruits per plant. The Pearson's coefficient of correlation was estimated to evaluate the associations between variables. Positive and significant correlations were observed at $1 \%$ between "COL" x "FN" and between "COL" $x$ "PRD". The fruit necrosis was higher on coffees with higher yield and higher number of fruits per productive node. It is suggested that the field evaluation for resistance to fruit necrosis would be better if accomplished on coffee trees with high yield and high number of fruits per productive node.

Index terms: Antracnosis, Coffea, coffee breeding, Colletotrichum gloeosporioides, cultivars.

(Recebido em 18 de maio de 2006 e aprovado em 10 de maio de 2007)

\section{INTRODUÇÃO}

Várias espécies de fungo do gênero Colletotrichum causam diferentes doenças na cultura do café. A mais conhecida é $C$. kahawae causador da doença "Coffee Berry Disease" (CBD), que ocorre na África. Entretanto, recentemente, outras espécies do gênero Colletotrichum vêm sendo associadas a sérios danos para a cafeicultura brasileira.

Em Minas Gerais, a partir de lesões jovens presentes nas folhas de cafeeiros adultos, foi isolado C. coffeanum, agente causal da mancha-manteigosa, e de mudas com lesões foi isolado C. gloeosporioides. Em testes de patogenicidade com frutos verdes destacados, tanto $C$.

\footnotetext{
*Área Ciências Agrárias

'Doutorando - Área de Melhoramento e Genética Vegetal/AMG - Instituto Agronômico do Paraná/lAPAR - Rodovia Celso Garcia Cid, Km 375 - Três Marcos - Cx. P. 481 - 86047-902 - Londrina, PR - gustavosera@uol.com.br; itods@uol.com.br

2Doutor - Área de Melhoramento e Genética Vegetal/AMG - Instituto Agronômico do Paraná/lAPAR - Rodovia Celso Garcia Cid, Km 375 - Três Marcos Cx. P. 481 - 86047-902 - Londrina, PR - tsera@uol.com.br

${ }^{3}$ Técnico Agrícola - Área de Melhoramento e Genética Vegetal/AMG - Instituto Agronômico do Paraná/lAPAR - Rodovia Celso Garcia Cid, Km 375 - Três Marcos - Cx. P. 481 -86047-902 - Londrina, PR - azevedoja@pop.com.br; geneticacafé@iapar.br; ribeiroclayton@gmail.com
} 
coffeanum quanto C. gloeosporioides se mostraram patogênicos (DORIZZOTTO, 1993). Atualmente, sabe-se que o C. coffeanum relacionado por Dorizzotto (1993) é a espécie C. gloeosporioides, provavelmente, uma raça específica denominada mancha-manteigosa por OrozcoMiranda (2003). Esse autor identificou isolados de Colletotrichum spp. como pertencentes às espécies $C$. acutatum e C. gloeosporioides, as quais diferiram claramente de $C$. kahawae e foram obtidos de cafeeiros do Estado de Minas Gerais. Os isolados de C. acutatum foram obtidos a partir de sintomas de necrose em folhas e ramos, e em ramos com seca de ponteiros. Os isolados de $C$. gloeosporioides foram obtidos a partir dos seguintes sintomas: mancha-manteigosa em folhas e frutos; necrose em folhas, frutos e ramos; seca de ponteiros em ramos e antracnose nos frutos. Esse mesmo autor considerou que os isolados de C. gloeosporioides que ocasionam os sintomas de mancha-manteigosa, seca de ponteiros e necrose em frutos, constituem raças patogênicas dessa espécie e propôs que os isolados desse fungo, que ocasionam a mancha-manteigosa, deve ser denominada como C. gloeosporioides raça mancha manteigosa.

Diferenças no comportamento de oito isolados de C. gloeosporioides, quanto à patogenicidade associados à análise de DNA, sugerem diferentes espécies e/ou patotipos (raças) patogênicos e não patogênicos, associados aos sintomas de antracnose nas folhas, ramos e frutos, em cafeeiros de Minas Gerais (JULIATTI et al., 2000).

Silva et al. (2005) identificaram C. gloeosporioides a partir de amostras de folhas, ramos e frutos escurecidos e necrosados das diferentes regiões cafeeiras do estado do Paraná.

As formas patogênicas e pouco agressivas de Colletotrichum spp. são encontradas causando diferentes sintomas. Esses ocorrem a partir da base dos ramos plagiotrópicos e se desenvolvem para a ponta. Os sintomas são: escurecimento e morte das estípulas dos nós; manchas irregulares necróticas próximas às margens das folhas e queda; desenvolvimento de manchas pardas no caule verde podendo levar a plântula à morte; lesões necróticas de pardas a negras em gemas, flores, chumbinhos e frutos, provocando a morte e a queda deles e enegrecimento e morte de ramos (PARADELA-FILHO et al., 2001), sendo a morte das estruturas reprodutivas e dos ramos as mais prejudiciais para o cafeeiro. Entretanto, Paradela-Filho et al. (2001) descreveram que de todos os sintomas descritos anteriormente, somente Colletotrichum spp. tem sido obtido em isolamentos e relatam a possibilidade da existência de diferentes isolados, uma vez que o fungo apresenta grande variabilidade em cultura. Também relatam que, raramente, em casos de ramos com sintomas de desfolha e seca descendente tem sido encontrada uma associação entre Colletotrichum spp. e Phoma spp. Os sintomas de seca de ramos apresentando colonização dos tecidos no sentido descendente da planta, caracteriza a forma saprofítica de Colletotrichum spp. (PARADELAFILHO \& PARADELA, 2001). No Instituto Agronômico do Paraná (IAPAR), em Londrina, o sintoma de necrose dos frutos associada ao Colletotrichum spp. é o mesmo descrito por Paradela-Filho et al. (2001) (Figura 1).

Períodos contínuos com umidade elevada ( 7 a 10 dias de chuva) e temperaturas amenas, em torno de $22{ }^{\circ} \mathrm{C}$, favorecem o desenvolvimento de Colletotrichum spp. que passa da fase saprofítica para a parasítica (PARADELA-FILHO et al., 2001). Orozco-Miranda (2003) demonstrou que o crescimento micelial e esporulação de isolados de C. gloeosporioides, em meio malte-ágar, foi maior a $25^{\circ} \mathrm{C}$.

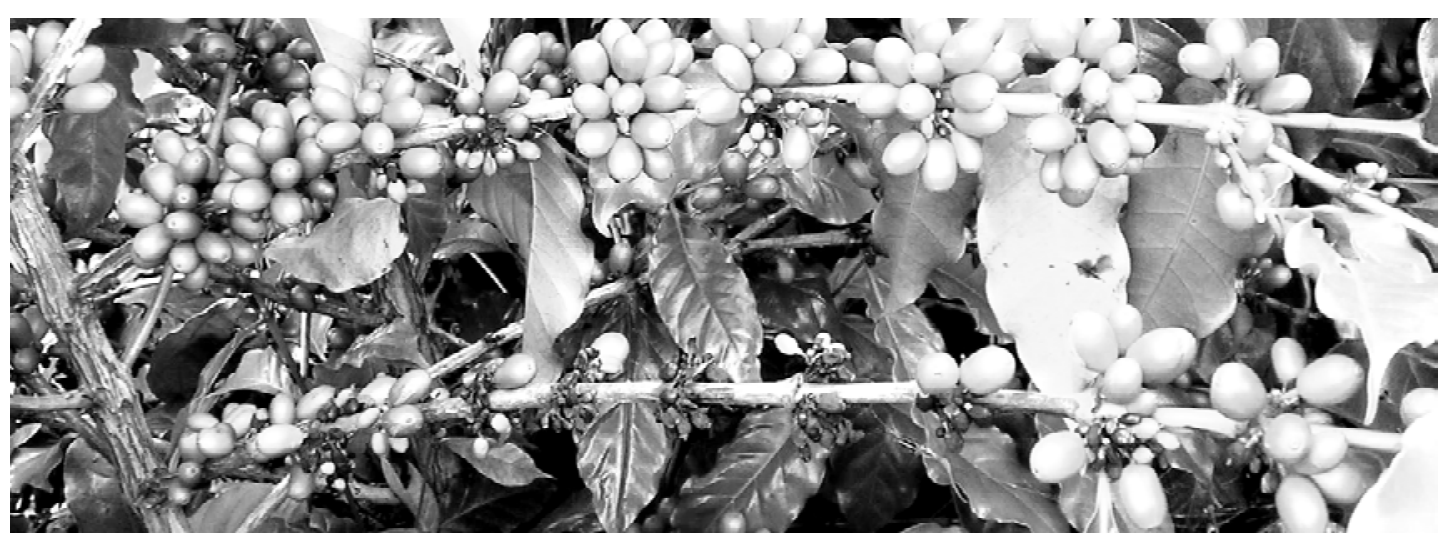

Figura 1 - Necrose de frutos associada à presença de Colletotrichum spp. (IAPAR, Londrina, PR, fevereiro de 2005). 
Sera et al. (2005b) sugeriram que cafeeiros com poucos frutos por nó produtivo, provavelmente, apresentam menos necrose de frutos associada ao Colletotrichum spp. do que em cafeeiros com alta quantidade de frutos, porém nenhum estudo de correlação foi realizado entre essas variáveis.

Assim, objetivou-se aqui verificar a existência de associação entre a necrose de frutos associada ao Colletotrichum spp., com os sintomas descritos por Paradela-Filho et al. (2001), com a quantidade de frutos por nó produtivo e com a produção em genótipos de café arábica.

\section{MATERIAL E MÉTODOS}

O ensaio de campo foi instalado em 20 de agosto de 2002 na Estação Experimental do IAPAR em Londrina, PR, Brasil, no espaçamento $2,5 \mathrm{~m}$ x 0,5 m. A altitude local é de $585 \mathrm{~m}$, com média anual histórica de temperatura, precipitação e umidade relativa do ar, respectivamente, de $20,8^{\circ} \mathrm{C}, 1610 \mathrm{~mm}$ e $71 \%$.

No IAPAR, todas as amostras de folhas, ramos e frutos escurecidos e necrosados de cafeeiros (Coffea arabica L.), com os mesmos sintomas descritos por Paradela-Filho et al. (2001), foram identificados como Colletotrichum spp. por Paradela-Filho (2004, informação pessoal) e como C. gloeosporioides por Silva et al. (2005).

As variáveis necrose dos frutos e quantidade de frutos por nó produtivo foram avaliadas em dezembro de 2004, em cafeeiros com três anos de idade com alta quantidade de frutos. Essas avaliações foram realizadas nos estádios de fruto "chumbinho" e expansão dos frutos. A variável produção foi avaliada em maio de 2005.

Os genótipos avaliados foram: IAPAR-59, Tupi IAC 1669-33, Obatã IAC 1669-20, Costa Rica 95 T-8667, Catuaí Vermelho IAC-99, Ouro Verde IAC H5010-5, Rubi MG-1192, Mundo Novo IAC 464-12, Catucaí 785-15, Catucaí Vermelho 4-79, Catucaí-Açú, Icatu Precoce IAC-3282, Palma II, Rume Sudan IAC-1139 e Villa Sarchi (Icafé - Costa Rica). Além dessas cultivares, foi avaliado o genótipo Catuaí "Arrepiado". No total, foram avaliadas 336 plantas, sendo em torno de 20 plantas por genótipo.

A necrose de frutos associada à presença de Colletotrichum spp. ("COL") foi avaliada atribuindo-se notas de 1 a 5 , onde: $1=0 \%$ a $5 \%$ de frutos necrosados; $2=6 \%$ a $10 \%$ de frutos necrosados; $3=11 \%$ a $20 \%$ de necrose; $4=21 \%$ a $40 \%$ de necrose; e $5=$ mais do que 41 $\%$ de frutos necrosados.

Foi avaliada a quantidade média de frutos por nó produtivo da planta ("FN"), dos melhores ramos produtivos, seguindo uma escala de notas de 1 a 5, onde:
1 = 0 a 3 frutos/ nó; 2 = 4 a 7 frutos/ nó; 3 = 8 a 11 frutos/ nó; $4=12$ a 15 frutos/ nó; e 5 = mais do que 15 frutos/ nó (Figura 2).

A avaliação da produção ("PRD") foi visual e baseada em litros de frutos-cereja por planta.

Foi usado o software Genes (CRUZ, 2001) para estimar a correlação de Pearson entre as variáveis "COL", "FN" e "PRD". A significância foi verificada pelo teste t. Além das correlações entre as variáveis de todas as plantas (Corr. todas), foram estimadas correlações separadas das 91 plantas das cultivares mais resistentes (Corr. resist.) e das 245 plantas das cultivares mais suscetíveis (Corr. suscet.). Isso porque em cultivares mais resistentes ocorre pouca necrose de frutos mesmo em cafeeiros com alta quantidade de frutos por nó produtivo.

Foram consideradas cultivares mais resistentes, aquelas com notas médias de 1 até 2,5 e cultivares mais suscetíveis, com notas médias de 2,6 até 5,0.

\section{RESULTADOS E DISCUSSÃO}

A associação entre a variável "COL" com a "FN" foi positiva e significativa a $1 \%$ para a "Corr. todas" $(r=$ $0,3512)$ e para a "Corr. suscet." ( $r=0,4987)$, enquanto que a "Corr. resist." ( $r=0,0523)$ foi não significativa. Isso indica que a maior freqüência de frutos necrosados associados à presença de Colletotrichum spp. ocorreu em parte em razão da maior quantidade de frutos por nó produtivo $(\mathrm{r}=$ $0,4987^{* *}$ ) (Tabela 1) do mesmo modo que Sera et al. (2005b) sugeriram.

Na maioria dos genótipos foi observado aumento da necrose de frutos com o aumento da quantidade de frutos por nó, como foi o caso dos genótipos Palma II, IAPAR-59 III-1-10, Mundo Novo IAC 464-12, Icatu Precoce IAC-3282, Catuaí "Arrepiado", Catucaí 785-15, Rubi MG-1192, Rume Sudan IAC-1139, Ouro Verde IAC H5010-5, Catucaí-Açú e Villa Sarchi (Tabela 2). A maior incidência de necrose de frutos em plantas suscetíveis com maior quantidade de frutos por nó, provavelmente, ocorre pelo acúmulo de água nos pedúnculos de nós produtivos com muitos frutos, o qual faz com que aumente o período de molhamento no fruto, com conseqüente aumento da severidade de Colletotrichum spp. Segundo Paradela-Filho \& Paradela (2001), quanto maior o período de molhamento dos tecidos das plantas, maior é a colonização pelo fungo. Sera et al. (2004) verificaram mais necrose de frutos associada a esse fungo na região de Londrina, PR, dentro da copa de cafeeiros mais sombreados ou com menor incidência de luz e arejamento, o que aumenta o período de molhamento. 

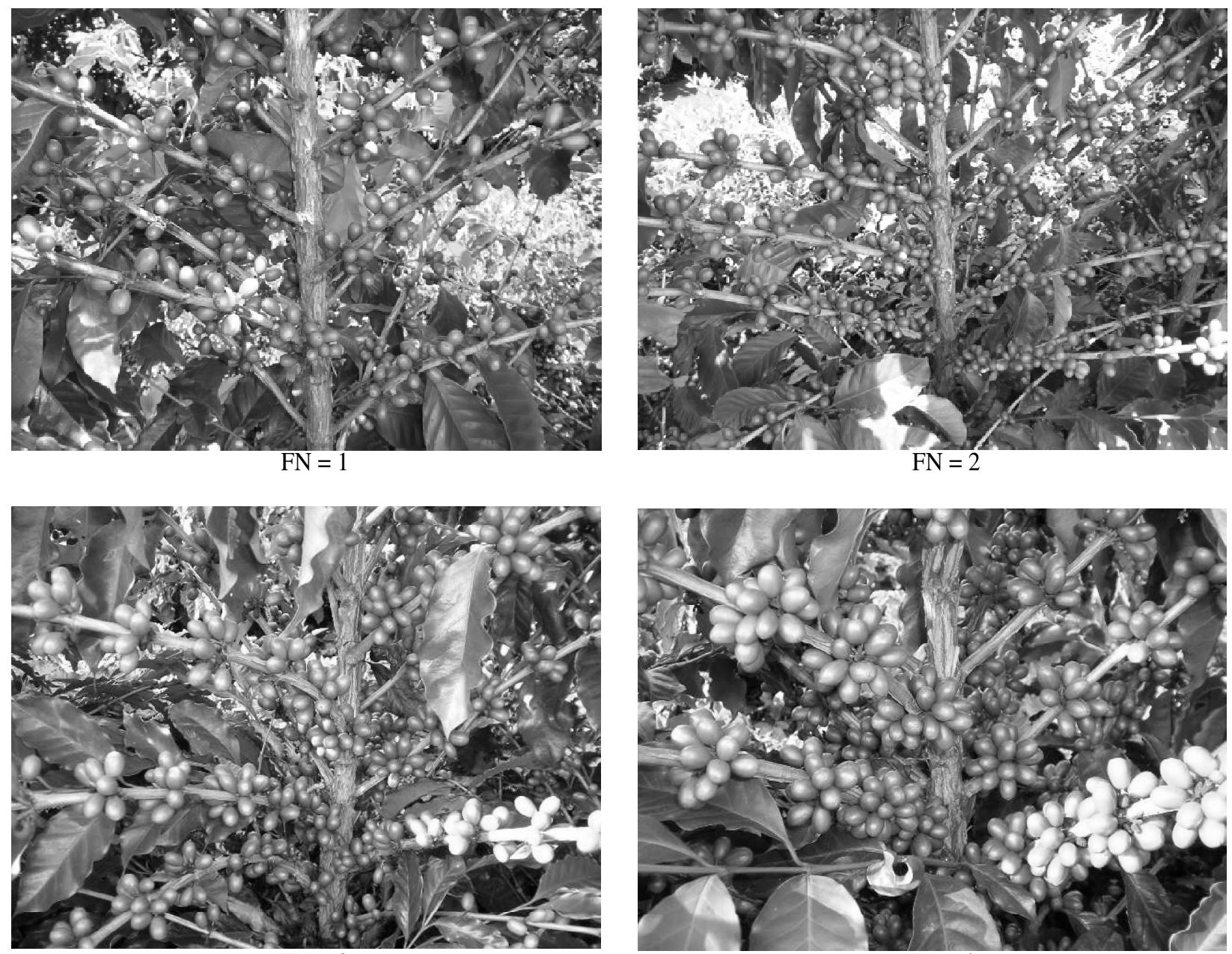

$\mathrm{FN}=3$

$\mathrm{FN}=4$

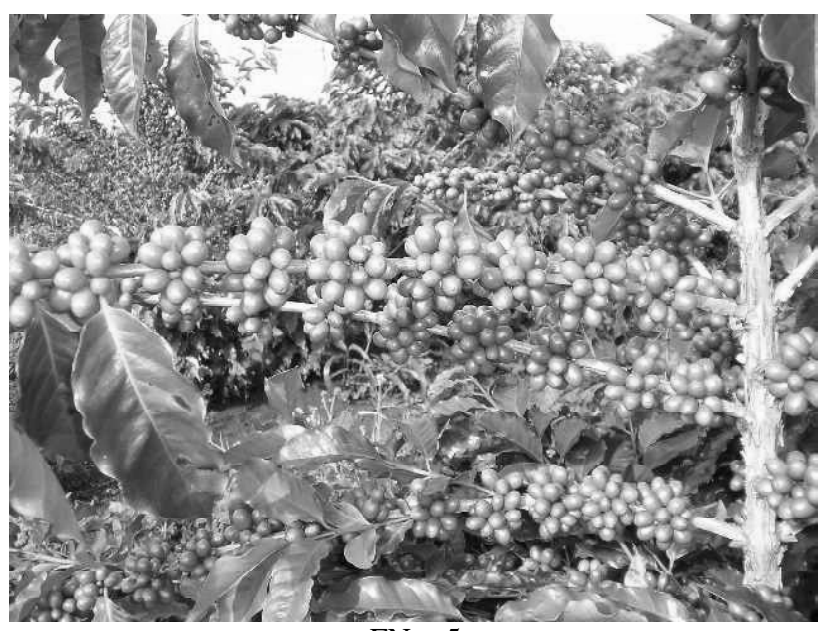

$\mathrm{FN}=5$

Figura 2 - Escala de notas de 1 a 5 da quantidade de frutos por nó produtivo (FN), usada na avaliação de cafeeiros no IAPAR (Londrina - PR). 
Tabela 1 - Correlações entre as variáveis necrose de frutos associada ao Colletotrichum spp. (COL), quantidade de frutos por nó produtivo (FN) e produção (PRD) em cafeeiros arábicos avaliados no IAPAR (Londrina - PR - Brasil).

\begin{tabular}{|c|c|c|c|c|c|}
\hline \multicolumn{2}{|c|}{ Correlação de todas as plantas } & \multicolumn{2}{|c|}{ Correlação das mais resistentes } & \multicolumn{2}{|c|}{ Correlação das mais suscetíveis } \\
\hline Variáveis & Correlação (r) & Variáveis & Correlação (r) & Variáveis & Correlação (r) \\
\hline COL $x$ FN & $0,3512 * *$ & COL x FN & $0,0523^{\text {n.s. }}$ & COL $x$ FN & $0,4987 * *$ \\
\hline COL $x$ PRD & $0,2457 * *$ & COL $x$ PRD & $0,0940^{\text {n.s. }}$ & COL $x$ PRD & $0,3344 * *$ \\
\hline
\end{tabular}

** Significativo a $1 \%$ de probabilidade pelo teste $\mathrm{t}$.

Tabela 2 - Notas médias da necrose de frutos (COL) de plantas com notas 1, 2, 3, 4 e 5 da variável quantidade de frutos por nó produtivo (FN) dos diferentes genótipos avaliados. As avaliações das variáveis COL e FN foram realizadas em cafeeiros com três anos de idade no IAPAR, Londrina, PR, em dezembro de 2004.

\begin{tabular}{cccccc}
\hline Genótipos $^{(1)}$ & \multicolumn{5}{c}{ Notas de FN $^{(2)}$} \\
\cline { 2 - 5 } Palma II & 1 & 2 & 3 & 4 & 5 \\
\hline Costa Rica 95 T-8667 & --- & 3,17 & 4,50 & 4,29 & 4,50 \\
IAPAR-59 III-1-10 & --- & 4,00 & --- & 3,50 & 4,17 \\
Mundo Novo IAC 464-12 & --- & 1,00 & 4,00 & 3,86 & 4,50 \\
Icatu Precoce IAC-3282 & 1,60 & 3,20 & 3,20 & --- & --- \\
Catuaí “Arrepiado" & 1,17 & 2,85 & 3,00 & --- & --- \\
Catucaí 785-15 & 1,50 & 3,25 & 3,50 & --- & --- \\
Rubi MG-1192 & -- & 2,50 & 3,80 & 3,63 & 3,33 \\
Rume Sudan IAC-1139 & 1,06 & --- & 4,00 & 3,00 & --- \\
Tupi IAC 1669-33 & 1,00 & 2,00 & 3,20 & 3,00 & --- \\
Ouro Verde IAC H5010-5 & --- & --- & 2,70 & 2,78 & 2,50 \\
Catucaí-Açú & --- & 2,00 & 2,58 & 3,00 & 1,00 \\
IAPAR-59 (originado de várias plantas) & 1,00 & 2,00 & 2,67 & 3,14 & 2,13 \\
Villa Sarchi (Icafé - Costa Rica) & --- & 4,00 & 2,33 & 3,00 & 2,50 \\
Tupi IAC 1669-33 (IAPAR 88480-8) & 1,25 & 1,67 & 2,33 & --- & 4,00 \\
IAPAR-59 III-1-9 & 2,80 & --- & 2,25 & 2,71 & 1,33 \\
Catuaí Vermelho IAC-99 & --- & 1,50 & 2,20 & 2,20 & 2,43 \\
Catucaí Vermelho 4-79 & 1,07 & 2,00 & 2,00 & 2,00 & 1,00 \\
Obatã IAC 1669-20 & 1,00 & 2,00 & 2,00 & 2,00 & 1,00 \\
\end{tabular}

(1) Genótipos ordenados decrescentemente com base na nota média de COL.

(2) Três traços (—) indicam ausência de plantas com a respectiva nota de FN.

Também foi observada associação positiva e significativa a $1 \%$ entre as variáveis "COL" e "PRD" para a "Corr. todas" ( $\mathrm{r}=0,2457)$ e para a "Corr. suscet." $(\mathrm{r}=$ $0,3344)$, indicando que, em plantas suscetíveis com mais produção a necrose de frutos foi mais intensa.

Tanto as correlações COL x FN como COL x PRD das plantas das cultivares mais resistentes não foram significativas. Nas plantas mais resistentes não ocorreu aumento significativo da necrose de frutos em cafeeiros com mais frutos por nó produtivo e com mais produção, como pode ser observado para as cultivares Obatã IAC 1669-20, Catucaí Vermelho 4-79, Catuaí Vermelho IAC-99 e IAPAR-59 III-1-9 (Tabela 2). É possível que resistência à necrose de frutos seja derivada de Coffea canephora Pierre, 
pois Obatã IAC 1669-20 (“Sarchimor”), Catucaí Vermelho 4-79 e IAPAR-59 III-1-9 ("Sarchimor") possuem genes dessa espécie. Orozco-Miranda (2003) e Sera et al. (2005b) também identificaram progênies com resistência à necrose de frutos e ao C. gloeosporioides, respectivamente, nos germoplasmas Sarchimor e Catucaí. Vossen \& Walyaro (1980) relataram que a resistência do Híbrido de Timor ao C. kahawae, provavelmente, é originada de $C$. canephora. Entretanto outros genes maiores ou menores podem atuar na resistência à necrose de frutos, já que Catuaí Vermelho IAC-99 não é derivada da espécie $C$. canephora.

A maioria dos genótipos apresentou mais necrose de frutos a partir de plantas com nota de FN igual a 3, como é o caso dos genótipos Palma II, IAPAR-59 III-110, Catucaí 785-15, Rubi MG-1192, Rume Sudan IAC-1139, Ouro Verde IAC H5010-5, Catucaí-Açú e Villa Sarchi (Tabela 2). Assim, sugere-se que a avaliação da resistência à necrose de frutos, associada ao Colletotrichum spp., em condições de campo, seja realizada em cafeeiros com alta produção e com notas de FN 3, 4 e 5. Isso aumentará a eficiência na identificação de fontes de resistência à necrose de frutos, evitando-se avaliar planta suscetível com poucos frutos por nó como sendo mais resistente. Sera et al. (2005b) não consideraram as avaliações de plantas com notas de FN igual a 1 ou 2 para identificar fontes de resistência à necrose de frutos. Entretanto, algumas plantas suscetíveis e altamente suscetíveis apresentam alta quantidade de frutos necrosados mesmo com notas de "FN" 1 e 2, como pode ser observado nos genótipos Palma II, Costa Rica 95, Mundo Novo IAC 464-12, Icatu Precoce IAC-3282, Catuaí “Arrepiado", IAPAR-59 (originado de várias plantas) e Tupi IAC 166933 (IAPAR 88480-8) (Tabela 2). Assim, cafeeiros com notas de FN 1 e 2, porém suscetíveis $(\mathrm{COL}=4$ e 5), devem ser considerados nas avaliações. A necrose de frutos associada ao Colletotrichum spp. pode ser considerada um problema fitopatológico grave, pois mesmo em cafeeiros com notas de FN 1 e 2, com pouca produção, e muitas vezes indiferentemente de fatores de stress na lavoura ocorre alta incidência de necrose dos frutos.

Segundo Pascholati (1995), C. gloeosporioides produz a enzima cutinase para a degradação da cutícula. Juliatti \& Silva (2001) citaram que a taxa de germinação dos conídios desse fungo depende do substrato e de outros fatores, sendo muito mais alta nas pétalas florais e frutos novos que possuem cutícula delgada, permitindo maior e mais rápida difusão de substâncias nutritivas para o ponto de infecção. Assim, sugere-se também que as avaliações da resistência à necrose de frutos, em condições de campo, sejam realizadas em cafeeiros com frutos nos estádios chumbinhos e/ ou em expansão, como foi realizado nesse trabalho.

Em avaliações de campo para a resistência à necrose de frutos é necessário avaliar outras variáveis que influenciam na sua incidência, como o índice de luminosidade dentro da copa da planta (SERA et al., 2004), vigor vegetativo (SERA et al., 2004, 2005b) e quantidade de frutos por nó produtivo.

A não avaliação da variável FN e do índice de luminosidade dentro da copa da planta pode resultar em menor eficiência de seleção. Isso, porque, a não eliminação de plantas com notas de FN 1 e 2 e/ ou de plantas com alto índice de luminosidade resultará em aumento da variância ambiental, com conseqüente diminuição da variância genotípica e da herdabilidade da variável resistência à necrose dos frutos.

\section{CONCLUSÕES}

A necrose dos frutos foi mais intensa em cafeeiros com mais produção e com mais frutos por nó produtivo.

Recomenda-se que a avaliação da resistência à necrose de frutos associada à presença de Colletotrichum spp., em condições de campo, seja realizada em cafeeiros com alta produção e alta quantidade de frutos por nó produtivo.

\section{AGRADECIMENTOS}

Ao Instituto Agronômico do Paraná (IAPAR) pelo apoio financeiro e infra-estrutura concedida;

Ao CNPq pela bolsa de iniciação científica;

Ao PNP \& D Café / EMBRAPA.

\section{REFERÊNCIAS BIBLIOGRÁFICAS}

CRUZ, C. D. Programa Genes: versão Windows: aplicativo computacional em genética e estatística. Viçosa: UFV, 2001. $648 \mathrm{p}$.

DORIZZOTTO, A. Caracterização morfológica e patogenicidade de Colletotrichum sp. associados a cafeeiros (Coffea arabica L.) em dois municípios de Minas Gerais. 1993. 67 f. Dissertação (Mestrado) - Escola Superior de Agricultura de Lavras, Lavras, 1993.

JUliatti, F. C.; SILVA, S. A. da. Antracnose Colletotrichum gloeosporioides Penz. e outras espécies: manejo integrado de doenças na cafeicultura do cerrado. Uberlândia: UFU, 2001. p. 37-50. 
JULIATTI, F. C.; SILVA, C. C. N.; GUIMARÃES FILHO, L. R. Estudos das características fisiológicas e genéticas de isolados de Colletotrichum spp. coletados em lavouras cafeeiras (Coffea arabica) de Minas Gerais: testes de patogenicidade e análise molecular. In: SIMPÓSIO DE PESQUISA DOS CAFÉS DO BRASIL, 1., 2000, Poços de Caldas, MG. Resumos expandidos... Brasília, DF: Embrapa Café; Minasplan, 2000. v. 1, p. 215-218.

OROZCO-MIRANDA, E. F. Caracterização morfológica, molecular, bioquímica e patogênica de isolados de Colletotrichum spp. associados ao cafeeiro em Minas Gerais e comparação com Colletotrichum kahawae. 2003.147 f. Tese (Doutorado)-Universidade Federal de Lavras, Lavras, 2003.

PARADELA-FILHO, O.; PARADELA, A. L. O complexo Colletotrichum cafeeiro. In: ZAMBOLIM, L. (Ed.). Tecnologias de produção de café com qualidade. Viçosa: UFV, 2001. p. 269-275.

PARADELA-FILHO, O.; PARADELA，A. L.; THOMAZIELLO, R. A.; RIBEIRO, I. J. A.; SUGIMORI, M. H.; FAZUOLI, L. C. O complexo Colletotrichum do cafeeiro. Boletim Técnico IAC, Campinas, n. 191, 2001.

PASCHOLATI, S. F. Fitopatógenos: arsenal enzimático. In: BERGAMIN FILHO, A.; KIMATI, H.; AMORIM, L. (Eds.). Manual de fitopatologia. 3. ed. São Paulo: Agronômica Ceres, 1995. v. 1, p. 348.
SERA, G. H.; ALTÉIA, M. Z.; SERA, T.; PETEK, M. R.; ITO, D. S. Correlação entre a ocorrência de Colletotrichum spp. e outras características agronômicas em cafeeiros. Bragantia, Campinas, v. 64, n. 3, p. 435-440, 2005 a.

SERA, G. H.; ITO, D. S.; SERA, T.; PETEK, M. R.; MATA, J. S. da; AZEVEDO, J. A.; DOI, D. S.; COTARELLI, V. M. Associação da incidência de Colletotrichum spp. com características agronômicas em cafeeiros. SBPN Scientific Journal, São Paulo, v. 8, p. 19, 2004.

SERA, G. H.; SERA, T.; ITO, D. S.; AZEVEDO, J. A. de; RIBEIRO-FILHO, C.; PETEK, M. R.; MATA, J. S. da; DOI, D. S.; COTARELLI, V. M. Resistência de campo ao Colletotrichum spp. entre genótipos de café (Coffea arabica L.). In: SIMPÓSIO DE PESQUISA DOS CAFÉS DO BRASIL, 4., 2005, Londrina. Anais... Brasília, DF: Embrapa Café, 2005b. CD-ROM.

SILVA, M. R. L.; MENEGUIM, L.; GONÇALVES, J. S.; PISTORI, J. F.; LEITE JÚNIOR, R. P. Caracterização de Colletotrichum spp. associado ao cafeeiro no Estado do Paraná. In: SIMPÓSIO DE PESQUISA DOS CAFÉS DO BRASIL, 4., 2005, Londrina. Anais... Londrina: Embrapa, 2005. CD-ROM.

VOSSEN, H. A. M. van den; WALYARO, D. J. A. Breeding for resistance to coffee berry disease in Coffea arabica L. [S.l.: s.n.], 1980 . 